\title{
Research on the Application of Flipped Classroom in Java Programming Experiment Teaching
}

\author{
Zhuo $\mathrm{Li}^{1, \mathrm{a}}$ and Qi-xian Geng ${ }^{2, \mathrm{~b}^{*}}$ \\ ${ }^{1}$ College of Computer Science and Technology, Beihua University, Jilin, China \\ ${ }^{2}$ College of Mechanical Engineering, Beihua University, Jilin, China \\ a honeyton@126.com, b gengqixian@163.com
}

Keywords: Teaching mode, flipped classroom, Java programming, experiment teaching.

\begin{abstract}
Flipped classroom which changed the traditional teaching mode by way of reverse the process of knowledge transfer and knowledge internalization, is concerned and become a research focus of teaching reform in colleges and universities. Through analyzing the existing deficiency of Java programming curriculum experimental teaching, by using the basic theory of flipped classroom, the flipped classroom mode of Java programming experiment teaching is design and construction, and a new evaluation method of experimental teaching is put forward. The designed teaching mode can be used in the experiment teaching of Java programming. The results show that the flipped classroom application in experiment teaching can improve students' engineering practice ability, cultivate students' autonomous learning ability and innovation consciousness.
\end{abstract}

\section{Introduction}

As soon as it's officially launched by Sun Company in 1995, Java quickly become the global mainstream and widely used development language because of its characteristics of platform independence, security mechanism, high reliability, multi thread and network support, etc. In order to meet the needs of personnel training, many colleges and universities computer major and related major treat the Java language as the core curriculum of design program. Java programming is a very practical course, practical teaching is helpful to cultivate students' practical ability and application ability, and occupies a prominent position in Application-oriented Undergraduate Colleges[1]. Experimental teaching is a necessary part of the practical teaching, especially for the program design, experiment on the computer is an important part of the program design, to improve the quality of its teaching is of great significance to realize the goal of cultivating talents. But, at present due to the teaching of experiment course most still follow the traditional teaching mode, which makes most of the students in colleges and universities lack of practical project development experience, practical ability is relatively poor, it is difficult to meet the needs of high quality Java talents. Therefore, how to solve the situation of experimental teaching divorced from social demand, becomes the question which needs to discuss and research in Java programming experiment teaching.

In 2007 by the Colorado Rocky Mountain Forest Park high school two chemistry teachers, Jon Bergmann's and Aaron, SAMs, the flipped classroom teaching concept is put forward[2]. In 2011, Salman Khan had a speech entitled "Let's use video to reinvent education", the educational concept of "flipped classroom" in the United States began to pop, and spread all over the world. In China, some primary and secondary schools, such as Chongqing Jukui secondary school, Shenzhen Nanshan experimental school have introduced the flipped classroom teaching mode [3].With the successful application of the teaching mode, some colleges and universities gradually carry out trying to research and apply the teaching mode, but most of them aim at theory course teaching, the research on the application of the flipped classroom to the experimental teaching is still less. After analyzing some problems existing in the course of traditional experiment teaching at present, this paper puts forward that the flipped classroom is applied in the experiment teaching, and the experimental teaching mode based on the flipped classroom is designed for the Java programming 
course. Practice results show that, with flipped classroom applied in experiment teaching, is helpful to improve students' abilities of programming and engineering practice, and provides new ideas and useful attempt for the experimental teaching reform in Application-oriented Undergraduate Colleges.

\section{The Existing Problems of JAVA Programming Experiment Course}

\section{A. Less Experimental Hours, Affecting the Experimental Effect}

At present, there are many courses in colleges and universities, which lead to the class hour be compressed. Although many colleges and universities in order to improve students' practical ability, increase the number of experimental teaching, but the number of hours each experiment is still maintained at 2 3 hours. Hours of experiment in class is limited, for some comprehensive and design experiments, the number of experimental hours is obviously insufficient. Therefore, teachers in the experimental teaching or reduce the experimental requirements and the difficulty of the subject, or in the course of the experiment, the students do not finish the task within the specified time, so that students do not get enough training and practice, resulting in poor experimental results.

B. The Experiment Content is Single, Lack of Creativity

From the experimental project, the main is a single basic type, knowledge type, verification type experiment, the comprehensive and innovative experimental content is less. And some comprehensive experiment is basically a replica of the implementation of some teaching cases; the students' idea is limited. If students have no case reference to do independent project design, they will feel the difficulties encountered many specific problems.

C. Lack of Discussion and Communication in the Course of the Experiment

For the Java programming experimental course of traditional teaching, usually treat the class as the unit of experiment teaching. A class of 40 students in a computer room, according to teachers' pre-arranged experimental subject, code input, debugging and running, it is very difficult for the teacher to interact with each student face-to-face. In addition, due to the shortage of experimental time, there are not many opportunities for exchange between students; students with good foundation and strong practical ability have been busy with the completion of their own experimental topics, and some students with poor foundation and practical ability, in the experiment is very difficult to solve the problems they encounter through communication with their students, the effect of the experiment is affected.

D. Experimental Examination Method be not Perfect

At present, for the Java programming experimental class, most of the experimental results which evaluate students' experimental effect comes from the examination of the results of the program running, and combined with the experimental report of the students [4]. But in the experimental class, because teachers cannot monitored every student's experimental process, also due to the program can be copied, some students cope with the teachers through copying program in the experimental process, experimental report also exist plagiarism phenomenon, as a result, the class test results given by teachers often cannot objectively reflect the real situation of students' learning.

\section{The Feasibility of Using the Flipped Classroom Teaching Mode in the Course of JAVA Programming}

In order to solve the problems existing in the traditional Java program design in the experiment, we will consider the flipped classroom teaching mode to be introduced into the experimental teaching, the feasibility is discussed. The flipped classroom teaching mode is the subversion of the traditional teaching mode, in the flipped classroom, the students autonomous learning before class according to the teacher pre provide learning video, in the process of learning, the students determine their own learning time, place and schedule; after the completion of the study, they collate the contents of the study and ask questions. The classroom has become a place of knowledge internalization. In the classroom, students can seek help from their teachers and classmates to the 
doubtful problem they meet in pre class learning, expand discussion and exchange, answering questions, teachers in this process can provide students with more personalized guidance, so that students can understand the knowledge more deeply. So, flipped classroom is not simply a synonym for online learning, in addition to the students to conduct in-depth study through the network resources before class, in the classroom between teachers and students, students can be more effective in the face of interactive learning exchange, is the important value of the flipped classroom. To apply the flipped classroom in the experimental teaching, the students carry on the independent study to the experiment content and complete the experiment through network before the experiment. In the experimental class, you can discuss with your teachers and students to the problems which encountered in the process of your independently complete the experiment, from the aspect of time, flipped classroom extend the time of the experiment, make up the limitation of the experimental class hours. In addition, in the experimental class, flipped classroom provides teachers and students more time for face-to-face communication, and teacher can provide students with more targeted guidance, arrange some comprehensive and strong engineering experimental subject, to meet the different levels of students' learning needs. In the experimental course of flipped classroom, students' learning process can be better controlled by teachers, so that it is beneficial for integrated comprehensive evaluation to students' learning. Although less research on the experimental teaching mode based on flipped classroom, Cao Hong-long and other[5] proposed methods to optimize the DSP experiment teaching by using the micro lesson and flipped classroom, and Guo Wen-ping [6] aims at the problems that the student experiment time is insufficient, the operation opportunity is less in the network engineering experiment teaching, put forward network engineering experiment teaching mode based on flipped classroom, in a certain extent, verify the feasibility of flipped classroom in the teaching experiment. In summary, introduce the flipped classroom teaching mode into the experimental teaching, which can make up for the shortcomings of the current experimental teaching. It is a positive attempt and exploration for the reform of the experimental teaching in colleges and universities.

\section{Design and Practice of Flipped Classroom Teaching Mode of JAVA Programming Experimental Class}

By using the basic theory of flipped classroom, and reference several flipped classroom teaching mode at home and abroad[7], we construct the experimental teaching mode of Java programming based on flipped classroom, as shown in Figure 1.The model is mainly divided into 3 parts: the experimental learning before class, classroom experiment and the evaluation summary after experimental class. Students carry on learning and deepening of knowledge before the experimental class through network classroom, WeChat group and other online platform, and complete the pre class learning and experimental tasks; in the experimental class, mainly carry on demonstration and report the results, and face to face communication with teachers and students to the questions discovered before the class learning; and complete the writing of the experimental report and learning summary after the experiment class. According to the experimental teaching mode of Java programming based on flipped classroom, we have carried on the practice from several aspects of the experiment teaching, such as the experimental class design, the experimental class activity development, the experimental evaluation and the summary and so on. 


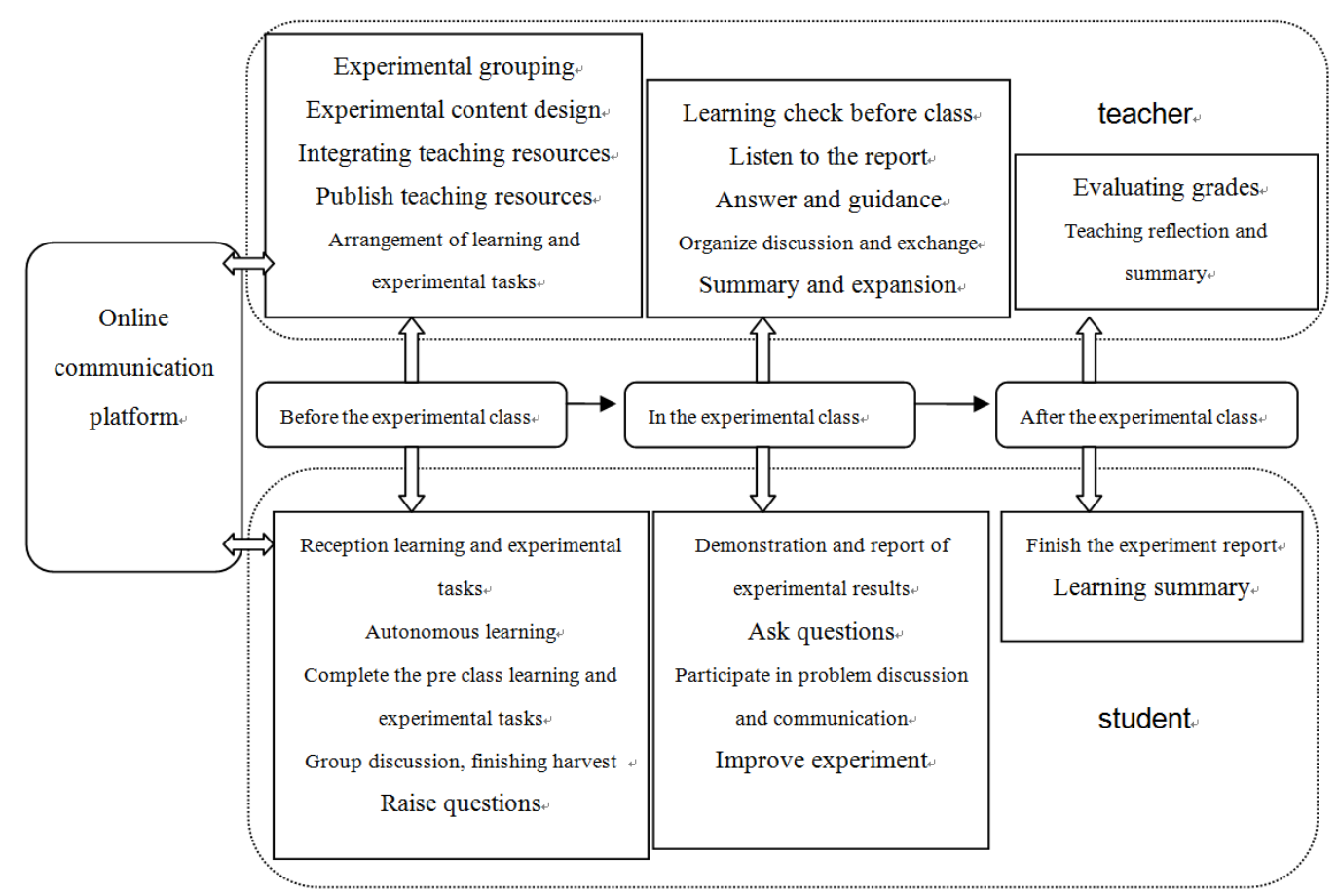

Fig.1. The experimental teaching model of Java programming based on flipped classroom

A. The Experimental Class Design

Before the experimental class, the teachers were grouped according to students' study foundation, personality characteristics and other factors, each group is composed of $3 \sim 4$ students. Among them, a student of good study foundation and practical ability serves as the group leader, who is responsible for the division of labor. In the design of the experiment content, we are based on the concept of CDIO advocated "project-based in education and learning"[8], the experimental content of the Java programming is dominated by the 3 level project, featured typical projects run through multiple knowledge points and the entire Java course. Through these projects, the main content of the experiment and these fragmented, scattered, relatively independent theoretical knowledge is run through, to make the content of the experiment an organic whole with a certain relation, which improve the students' interest and the experimental results, so as to embody the ability of analysis and design. Next, teachers need to arrange the experimental tasks, and according to the experimental content to product and collate the relevant learning resources, these resources include micro video, electronic courseware, animation and text information, etc. Resources should be simple and easy for students' autonomous learning. Experimental tasks and learning resources publish through the network classroom or other online exchange platform (for example: WeChat, etc.), to facilitate the learning of students anytime, anywhere.

In the design of the experimental task, we follow the projects selection basic principles of "practical, enough, can be used". Project design should be flexible and not too large to meet the needs of students at different levels. Before the experimental class, students download video teaching content and experimental tasks through the online platform, to develop their own learning plans and learning progress according to their ability to learn and the grasp level of knowledge.

During the study, students discuss and communicate to the team as a unit, the teacher can also interact with students, to answer questions raised by the students through the network teaching platform or WeChat group. In order to ensure the result of autonomous learning, students need to complete problem assigned by the teacher in the learning task list before class, and design experiment and initially complete the experimental task after autonomous learning. Finally, students need to summarize to problems encountered in autonomous learning or idea worthy of further discussion to the teachers and students, in preparation for entering the experimental classroom with problems. 


\section{B. Experimental Classroom Activities}

In the experimental class, teachers should first check the students' autonomous learning situation before class, to master the students' autonomous learning and experiment mainly by listening to the students experiment report; at the same time, teachers should conduct on-site FAQ according to students' problems at their autonomous learning stage, and demonstrate knowledge point aiming at the problems, unified demonstration of the common problems, individual solutions to the individual problems. In addition, the teacher can arrange some of the extended practical topics related to the experimental tasks according to the students' learning and discussion, students completed the scene, immediately submitted, teachers face to face reviews, the scene summarize the problem in the task implementation, and feedback the views to the students. This way not only can objectively evaluate the degree of students' internalization of knowledge, but also can help students to improve the experimental completion ability in the later period. In the experimental class, the students in the experimental group as a unit, report on the experimental task, explain the progress of the task, show their own experimental results, put forward the shortcomings in the experiment, as well as the ideas of further optimization, and put forward the problems encountered in the experiment, students in other group can offer advice and suggestions to solve these problems, collision sparks of wisdom through the discussion on the spot, through communication with teachers or students, so as to further improve their own experimental content.

C. Evaluation and Summary

After the experimental course, the teacher according to the experimental situation, made systematic analysis to the key and difficult points and the common problems of the students in the experiment, complete the experimental teaching summary and evaluate the students' experimental performance. The traditional "experimental results + experimental report" evaluation are not objective enough, can't adapt to the flipped classroom experiment mode. To this end, we add experiment process evaluation into the experimental evaluation, by combining the process evaluation and outcome evaluation, to evaluate students from multi-dimension. Among them, the process evaluation content $s$ mainly include the number of communication problem through WeChat groups or network classroom before class, the level of experimental proficiency reflected in the class report, the active degree of participating in the class discussion in the experimental class, etc; outcome evaluation contents include the rationality of the design of the experiment scheme, experimental function and innovation, the standardization of the experimental report, etc.

At the end of the experimental class, students should follow the experimental report writing specifications, carefully complete the experimental report, and summarize their own experience in the experiment, to complete the writing of the study summary. In this way, students can review the errors and improvement of innovation in the experiment, reflect on the summary and evaluation of teachers, through the reprocessing to the internalized knowledge of the brain, to further modify and improve the experimental results have been submitted, so as to continuously improve their hands-on ability and practical experience.

\section{The Teaching Effect of JAVA Experiment Class Based on Flipped Classroom}

According to the Java programming experiment class flipped classroom teaching mode designed in this paper, the pilot teaching is carried out. In the computer network engineering profession, an ordinary teaching class (40 people) was selected as a pilot; the other class of this profession is still using the traditional teaching methods. The final training test using the method of separation of teaching and examination, by the third party (a software company's project manager) issued a training program to all students, the pilot classes and non pilot class assessment results and the company's evaluation were compared, the results are shown in Table 1. 


\section{Table.1. EFFECT COMPARISON OF EXPERIMENTAL TEACHING BASED ON FLIPPED} CLASSROOM

\begin{tabular}{|c|c|c|c|}
\hline \multicolumn{2}{|r|}{ Class } & $\begin{array}{l}\text { Pilot } \\
\text { Class }\end{array}$ & $\begin{array}{l}\text { Non Pilot } \\
\text { Class }\end{array}$ \\
\hline \multirow{3}{*}{$\begin{array}{l}\text { Training } \\
\text { project } \\
\text { evaluation }\end{array}$} & $\begin{array}{l}\text { The highest score in the } \\
\text { class }\end{array}$ & 90 & 75 \\
\hline & $\begin{array}{l}\text { Percentage of students who } \\
\text { completed the difficulties }\end{array}$ & $75 \%$ & $35 \%$ \\
\hline & The class average score & 80 & 62 \\
\hline \multirow{3}{*}{$\begin{array}{l}\text { Company } \\
\text { evaluation }\end{array}$} & $\begin{array}{l}\text { The percentage of the } \\
\text { students whose software } \\
\text { can operate normally }\end{array}$ & $83 \%$ & $32 \%$ \\
\hline & $\begin{array}{l}\text { Student ratio of software } \\
\text { design reasonable }\end{array}$ & $85 \%$ & $60 \%$ \\
\hline & $\begin{array}{l}\text { Proportion of students with } \\
\text { innovative points }\end{array}$ & $60 \%$ & $10 \%$ \\
\hline
\end{tabular}

From the teaching effect comparison results shown in table 1, it can be seen that Java program design experiment course of the flipped classroom teaching mode can not only get the students recognition, but also achieved good effect in practical teaching, highlighting the advantages of flipped classroom teaching mode applied to the experimental course and the success of teaching reform.

\section{Conclusion}

Java programming course has more content, more abstract theory, limited hours, strong practical characteristics, the students understand and master have a certain degree of difficulty. Due to the restrictions of various conditions, there are many shortcomings in the implementation process of the experimental course as an auxiliary of teaching theory. This paper analyzes the feasibility of by using the flipped classroom teaching mode to solve the problems of traditional experimental teaching mode and builds the experimental teaching mode based on the flipped classroom. Through the practice in Java experiment course, the results show that the experimental teaching mode is widely recognized by students, play the students learning initiative, help to improve the students' practical ability; it has played a positive role in improving students' ability to analyze and solve practical problems.

\section{Acknowledgement}

The research work is supported by Educational Science “The 13th Five-Year” Planning Project of Jilin Province of China(No.GH170089).

\section{References}

[1] DING Xue-mei. Application Research on Flipped Classroom Model in Experiment Teaching [J]. Research and Exploration in Laboratory, 2015 34(6) 207-212.

[2] LIU Jian-zhi, WANG Dan. Review of Research and Practice on Flipped Classroom at Home and Abroad [J]. Theory and Practice of Contemporary Education, 2014 6(2) 68-71.

[3] WANG Hong, ZHAO Wei, SUN Li-hui, LIU Hong-xia. The Design of Flipped Classroom Teaching Model-Analysis Based on Typical Cases at Home and Abroad [J]. Modern Educational Technology , 2013 23(8) 5-10.

[4] LI Zhuo, ZHANG Shu-ying, ZHAO Jin-yan. Research and practice of teaching reform of Java Technology course [J]. Software Guide , 2014 13(12) 176-177.

[5] CAO Hong-long, HU Jian-ling, YU Yi-biao, SHAO Lei, LIU Xue-guan. On DSP Technology Experimental Teaching Based on Flipped Classroom and Micro-lecture [J]. Journal of 
Southwest China Normal University (Natural Science Edition), 2015 40(10) 191-196.

[6] GUO Wen-ping, CHEN Ying, ZHAO Xiao-ming. Teaching Design of Network Engineering Experimental Course Based on Flipped Classroom [J]. Experimental Technology and Management, 2015 32(5) 35-38.

[7] YANG Jian. Research on the application of the flipped classroom in experimental teaching [J]. Prospect of Science and Technology, 2015 (12) 142-143.

[8] ZHA Jian-zhong. On the CDIO Model under the Strategy of Learning by Doing [J]. Research on Higher Engineering Education, 2008 (3) 4-6. 